\title{
Mitral Valve Replacement in Senegal (West Africa): Indication and Short-Term Outcomes
}

\author{
Abdel-Kémal Bori Bata ${ }^{1}$, Amadou Gabriel Ciss ${ }^{1}$, Momar Sokhna Diop ${ }^{1}$, Papa Salmane Ba ${ }^{1}$, \\ Diagne Papa Amath ${ }^{1}$, Ndeye Fatou Sow ${ }^{1}$, Gaye Magaye ${ }^{1}$, Souleyman Diatta ${ }^{1}$, Mohamed Leye ${ }^{2}$, \\ Etienne Birame Sene ${ }^{3}$, Papa Adama Dieng ${ }^{1}$, Salimata Diallo ${ }^{1}$, Assane Ndiaye ${ }^{1}$, \\ Mouhamadou Ndiaye ${ }^{1}$ \\ ${ }^{1}$ Department of Thoracic and Cardiovascular Surgery FANN University Hospital, Cheikh Anta Diop University, Dakar, Senegal \\ ${ }^{2}$ Department of Cardiology FANN University Hospital, Cheikh Anta Diop University, Dakar, Senegal \\ ${ }^{3}$ Department of Anesthesiology FANN University Hospital, Cheikh Anta Diop University, Dakar, Senegal
}

\section{Email address:}

bbak@live.fr (Abdel-Kémal B. B.), cissgaby@yahoo.fr (Amadou G. C.), momarsokhna08@yahoo.fr (Momar S. D.), mansalb@yahoo.fr (Papa. S. Ba), diagnepapaamath@gmail.com (Diagne P. A.), zenefes@gmail.com (Ndeye F. S.), mgaye99@yahoo.fr (Gaye M.), soul.diatta@yahoo.fr (Souleyman D.), leyemohamed@gmail.com (Mohamed L.), biramsene@hotmail.com (Etienne B. S.), padiengsala@yahoo.fr (Papa A. D.), salicherie@gmail.com (Salimata D.), lazanat@yahoo.fr (Assane N.), mondiaye@orange.sn (Mouhamadou N.)

\section{To cite this article:}

Abdel-Kémal Bori Bata, Amadou Gabriel Ciss, Momar Sokhna Diop, Papa Salmane Ba, Diagne Papa Amath, Ndeye Fatou Sow, Gaye Magaye, Souleyman Diatta, Mohamed Leye, Etienne Birame Sene, Papa Adama Dieng, Salimata Diallo, Assane Ndiaye, Mouhamadou Ndiaye. Mitral Valve Replacement in Senegal (West Africa): Indication and Short-Term Outcomes. Cardiology and Cardiovascular Research. Vol. 2, No. 1, 2018, pp. 15-18. doi: 10.11648/j.ccr.20180201.14

Received: December 12, 2017; Accepted: February 24, 2018; Published: April 10, 2018

\begin{abstract}
The West African countries have infrequent Cardiac Surgery Centers. Mitral valve replacement (MVR) from such countries raises important postoperative preoccupations. The aim of this study is to report indication and short-term outcomes of MVR at the Cardiac Surgery Center of the University Hospital in Dakar (Senegal). This is a retrospective analytical and descriptive study covering a period of 19 months (From January 2015 to July 2016). All patients with MVR associated or not with tricuspid valve repair were included in this study. Seventy-three (73) patients were eligible. The mean follow-up was $4.2 \pm$ 4 months (range, 1-12). The mean age was $30.4 \pm 13$ years (range, 9-64). There were $74 \%$ of female patients, $53 \%$ were in New York Heart Association class III. Preoperative diagnoses were mitral stenosis (31.5\%); mitral regurgitation (37\%) and mixed mitral disease (31.5\%). Crystalloid cardioplegia was performed in $92 \%$, mean CPB time was $79 \pm 21$ min, mean cross clamp time was $58 \pm 15.6 \mathrm{~min}$. Mitral valve exposure was performed by left atriotomy (93\%); $99 \%$ of mechanical prosthesis was performed. Tricuspid valve repair was performed concomitantly in $48 \%$ of patients. Overall Hospital mortality was $8 \%$. Postoperative complications were low output syndrome (19\%), pneumonia (12\%), surgical wound infection (8\%), Pleural effusion (7\%). During follow-up, no valve-related morbidity and mortality was recorded. Mechanical valve replacement in Senegal has acceptable early outcomes in terms of morbi-mortality. Preoperative diagnoses were represented in equivalent proportions by mitral stenosis; mitral regurgitation and mixed mitral disease. Our complications were predominantly low output syndrome and pleura pulmonary disorders.
\end{abstract}

Keywords: Cardiac Surgery, Mitral Valve Replacement, West Africa, Outcomes

\section{Introduction}

The prevalence of rheumatic heart disease (RHD) is estimated worldwide at 15.6 million people, affecting mostly socially and economically disadvantaged populations. In Africa, mitral valve disease represents about $60 \%$ of rheumatic valvular heart disease $[1,2]$. Although repairs are a preferred treatment modality many rheumatic mitral valves can only be replaced [3]. The first mitral valve replacement was made in 1960 by Starr [4]. The first OHS was performed in Senegal, it was performed 1996. Mitral valve replacement represents $75 \%$ of heart valve replacement in our Cardiac 


\section{Surgery Center.}

The aim of this study is to report indication and short-term outcome of mitral valve replacement (MVR) at the Cardiac Surgery Center of the University Hospital in Dakar (SENENAL).

\section{Method}

This is a retrospective analytical and descriptive study covering a period of 19 months (From January 2015 to July 2016). All patients with MVR associated or not with tricuspid valve repair were included in this study. During the study period, 73 patients were eligible. Ninety-three percent $(93 \%)$ of patients were Senegalese origin, the others were from West Africa. The mean follow-up was $4.2 \pm 4$ months (range, 1-12).

All analyses were conducted with IBM $^{\circledR}$ SPSS ${ }^{\circledR}$ Statistics Version 22 under a bilateral hypothesis with a type-I error set at $5 \%$. For descriptive analyses, the categorical variables were expressed as number and percentage; the quantitative variables were expressed as mean \pm standard deviation (SD) in case of Gaussian distribution, or by quartiles and range otherwise.

\section{Results}

The mean of age and body mass index were $30.4 \pm 13$ years (range, 9-64) and 18.7 \pm 3.4 (range, 14-28) respectively. Seventy four percent $(74 \%)$ of patient were female, $7 \%$ had previous surgery, $49 \%$ had previous manifestation of rheumatic fever. Fourty four percent (44\%) of patient were in New York Heart Association class II, 53\% in class III. Electrocardiogram were in normal sinus rhythm in $52 \%$ of cases, $48 \%$ in arrhythmia atrial fibrillation, $15 \%$ in right bundle branch block, $5.5 \%$ in atrioventricular block. Eighty percent $(80 \%)$ of patient had indirect sign of pulmonary arterial hypertension (PAH) on Chest X-ray, 95\% of cardiomegaly, $69 \%$ of left atrial dilatation sign. Transthoracic echocardiography characteristics are listed in table 1. Most of ultrasound descriptions were in favor of rheumatic valvular lesions (95\%): commissural fusions, the remodeling of the valve leaflets (stiffening and thickening), the calcification of the annulus, the shortening of the chordae tendineae: all combining in varying degrees.

Table 1. Preoperativetransthoracic echocardiography characteristics.

\begin{tabular}{|c|c|}
\hline Echocardiography characteristics & Values \\
\hline \multicolumn{2}{|l|}{ Mitral regurgitation $($ Frequency $=61)$} \\
\hline None & $16.5 \%$ \\
\hline I & $15 \%$ \\
\hline II & $22 \%$ \\
\hline III & $4 \%$ \\
\hline IV & $42.5 \%$ \\
\hline EROA: Mean \pm SD [range] & $54 \pm 22 \mathrm{~mm}^{2}[15-115]$ \\
\hline $\mathrm{R}$ Vol: Mean $\pm \mathrm{SD}$ [range] & $72 \pm 36 \mathrm{ml}[25-208]$ \\
\hline Vena contracta width: Mean \pm SD [range] & $6.5 \pm 2 \mathrm{~mm}[3-10]$ \\
\hline Mitral annulus diameter: & $52.4 \pm 10 \mathrm{~mm}[36-69]$ \\
\hline \multicolumn{2}{|l|}{ Mitral stenosis (Frequency=50) } \\
\hline Valve area: Mean $\pm \mathrm{SD}$ [range] & $0.97 \pm 0.5 \mathrm{~cm}^{2}[0.32-2.7]$ \\
\hline
\end{tabular}

\begin{tabular}{ll}
\hline Echocardiography characteristics & Values \\
\hline Mean gradient: Mean \pm SD [range] & $15.3 \pm 6 \mathrm{mmHg}[5-28]$ \\
Tricuspid regurgitation & \\
I & $18 \%$ \\
II & $63 \%$ \\
III & $5.5 \%$ \\
IV & $14 \%$ \\
sPAP Mean \pm SD [range] & $64 \pm 22 \mathrm{mmHg}[20-123]$ \\
\hline
\end{tabular}

R Vol: regurgitant volume EROA: effective regurgitant orifice area LVDD: Left ventricular diastolic diameter

LVSD: Left ventricular systolic diameter LVEF: Left ventricular ejection fraction SPAP: systolic pulmonary artery pressure

TAPSE: tricuspid annular plane systolic excursion RVDD: Right ventricular diastolic diameter LAD: Left atrial diameter

Preoperative diagnoses were mitral stenosis (31.5\%); mitral regurgitation $(37 \%)$ and mixedmitral disease $(31.5 \%)$. The term mixed mitral disease associates mitral regurgitation and mitral stenosis to significant degrees. These diagnoses were often symptomatic with severe echocardiographic criteria. Surgical approach was the median sternotomy in all cases. Cardiopulmonary bypass (CPB) had always been established between an aortic cannula and two vena cava cannulas. Operative data of the patients are listed in table 2 . In the case we performed a tricuspid valve plasty, De Vega's annuloplasty was performed in $90 \%$ of the cases; in the remaining cases, tricuspid annuloplasty was performed with an autologous pericardial prosthetic ring harvested intraoperatively. Early postoperative data (i.e., $<30$ days) are listed in table 3 .

Table 2. Operative data.

\begin{tabular}{ll}
\hline Operative characteristics & Values \\
\hline Cardioplegia & \\
Crystalloid & $92 \%$ \\
Blood & $8 \%$ \\
Central temperature & \\
Moderate hypothermia & $97 \%$ \\
Normothermia & $3 \%$ \\
CPB Time: Mean \pm SD [range] & $79 \pm 21$ min $[50-145]$ \\
Cross clamp time: Mean \pm SD [range] & $58 \pm 15.6$ min [33-126] \\
Mitral valve exposure & \\
Left atriotomy & $93 \%$ \\
Right atriotomy transseptal & $7 \%$ \\
Type of mitral prosthesis & \\
Mechanical prosthesis (St. Jude MedicalTM) & $99 \%$ \\
Bioprosthetic & $1 \%$ \\
Tricuspid valve repair & $48 \%$ \\
\hline
\end{tabular}

CPB: Cardiopulmonary bypass min: minutes.

Table 3. Early postoperative data.

\begin{tabular}{ll}
\hline Postoperative characteristics & Values \\
\hline Length of stay (days) & \\
\hline ICU Mean \pm SD [range] & $5 \pm 1.7[1-10]$ \\
Hospital Mean \pm SD [range] & $11 \pm 4[3-21]$ \\
Length of intubation Mean \pm SD [range] (hours) & $4.7 \pm 2.2[1-15]$ \\
\hline & \\
\hline Morbidity & \\
\hline Cardiac & $19 \%$ \\
Low output syndrome & $1 \%$ \\
Ventricular fibrillation & $3 \%$ \\
Atrioventricular block & \\
\hline
\end{tabular}




\begin{tabular}{ll}
\hline Morbidity & \\
\hline Cardiac arrest & $3 \%$ \\
Pleural effusion & $7 \%$ \\
Infectious & \\
Septicemia & $4 \%$ \\
Pneumonia & $12 \%$ \\
Surgical wound infection & $8 \%$ \\
Multiple organ failure. & $1 \%$ \\
Re-operation & $5.5 \%$ \\
Echocardiography & \\
Paraprosthetic leak (mild to moderate) & $7 \%$ \\
Tricuspid regurgitation (mild to moderate) & $29 \%$ \\
Transprosthetic gradient Mean \pm SD [range] & $3.6 \pm 1.4[1.5-7.3]$ \\
Postoperative LVEF Mean \pm SD [range] & $53 \pm 7.3[25-63]$ \\
Mortality & \\
ICU mortality (frequency-percentage) & $5(7 \%)$ \\
Overall Hospital mortality (frequency- percentage) & $6(8 \%)$ \\
\hline
\end{tabular}

ICU: intensive care unit LVEF: Left ventricular ejection fraction.

There were no neurological or renal complications. Five patients died from low out syndrome despite maximal inotropes with no mechanical heart support available at the time. One patient died from bleeding. Postoperatively all patients were started on intravenous heparin and Acenocoumarol after the removal of temporary electrode epicardial pacing. Heparin was stopped when the target international normalized ratio (INR) of 3.5 - 4.5 was attained and continued for all patients with mechanical valves. Follow up post discharge was through by clinic visits. During follow-up, no valve-related morbidity and mortality was recorded. Post-operative NYHA functional class varied between Classes I and II in all patients.

\section{Discussion}

Mitral valve replacement represents $75 \%$ of heart valve replacement in our Cardiac Surgery Center. This varies between 71 and $80 \%$ in the African series [5, 6, 7]. In other continents, it has accounted for $25-37 \%$ of heart valves replacement $[8,9]$. Our data showed that patients who benefited of MVR were young, with a mean age of $30.4 \pm$ 13 years and a female predominance (74\%). This predominance in young and female populations can be superimposed on the results of the literature $[3,6,10]$. Indeed, this characteristic corresponds to the epidemiology of rheumatic mitral disease [1]. The rheumatic etiology is predominant in most series $[3,5,11]$.

There is a difference in the distribution of our preoperative diagnoses and those of other series. Zilla et al. [3] reported $11 \%$ of MS; $21 \%$ of MR; $68 \%$ of mixed. Nwiloh et al. [5] reported $16 \%$ of MS; $26 \%$ of MR; $58 \%$ of mixed. Zouaoui et al. [11] reported $30 \%$ of MS; $11 \%$ of MR; $60 \%$ of mixed.

Our mean cross clamp time is similar too those series: 59 min; however, our mean CPB time is is lower than others is lower than others: 92 min [11]. In a context of mitral valve replacement, the rate of tricuspid valve repairing varies between 15 and $40 \%[6,7,10,11]$. These proportions are clearly lower than our series: $48 \%$. This finding might be attributed to the severity of tricuspid regurgitation and PAH of the patients. Prophylactic tricuspid valve annuloplasty in patients with dilated tricuspid annulus undergoing mitral valve surgery was associated with a reduced rate of tricuspid regurgitation progression, improved right ventricular remodeling, and better functional outcomes [12].

There is a great deal of controversy over the outcomes of the transseptal (TS) and left atriotomy (LA) approaches to the mitral valve. In our practice, we used preferentially LA approach (93\%) showing to the frequent dilatation of left atrium. Nevertheless, the TS approach is still a valuable approach to mitral valve diseases, especially in patients with a small left atrium and combined tricuspid and mitral valve operations. However, TS approach was associated with higher pump and cross-clamp times and risk of postoperative atrial fibrillation [13].

We used predominantly crystalloid cardioplegia; however, the current trend is blood cardioplegia. We have also used predominantly the mechanical prostheses $(99 \%)$; this use varies between 70 and $90 \%$ in other series $[5,6,14]$. We have preferentially used these last because of the young age of our patients, but also the high cost of the operation inaccessible to a socio-economically disadvantaged population. Furthermore, it was felt that obtaining funding for future reoperation from bioprosthetic structural valve failure was highly unlikely for most of these patients.

The overall hospital mortality varies between 4 and $11.5 \%$ in other series $[5,6,11]$. Predictors of early mortality are: age $>60$ years, left ventricular dysfunction and preoperative PAH; the presence of atrial fibrillation. Our complications were predominantly low output syndrome, pneumonia, pleural effusion and surgical wound infection. This preponderance of low output syndrome, pleura pulmonary disorders has been found in other series $[6,11]$. None of our patients developed postoperative severe tricuspid regurgitation. Moderate preoperative TR is a significant risk factor for severe postoperative tricuspid regurgitation in patients undergoing mitral valve surgery [15]. The aggressive application of tricuspid valve repair can prevent it.

\section{Conclusion}

Mechanical valve replacement in Senegal has acceptable early outcomes in terms of morbi-mortality. Preoperative diagnoses were represented in equivalent proportions by mitral stenosis; mitral regurgitation and mixed mitral disease. Complications were predominantly low output syndrome, pleura pulmonary disorders. There were no neurological or renal complications. The overall hospital mortality is superimposed to those of the literature. By improving care and monitoring in intensive care unit; we could reduce our morbidity and mortality.

\section{Conflict of Interest}

All the authors do not have any possible conflicts of interest. 


\section{References}

[1] Kingué S, Ba SA, Balde D, Diarra MB, Anzouan-Kacou JB, Anisubia B, Damorou JM, Ndobo P, et al. The Valvafric study: A registry of rheumatic heart disease in Western and Central Africa. Arch Cardiovasc Dis. 2016; 109 (5):321-9.

[2] Balaka A, Tchamdja T, Djibril MA, Djagadou KA, Tchandana M, Damorou F, Agbétra A. Valvular heart disease in hospitals in Lome (Togo). Pan Afr Med J. 2015; 20:168.

[3] Zilla P, Koshy J, Brink J, Human P. Mitral valve replacement for rheumatic heart disease in Southern Africa. Journal of Cardiothoracic Surgery. 2013; 8 (Suppl 1):O294. doi:10.1186/1749-8090-8-S1-O294.

[4] Leguerrier A, Flecher E, Fouquet O, Lelong B. Prothèses valvulaires cardiaques. EMC - Cardiologie. 2009; 30:1-31.

[5] Nwiloh JO, Oludara MA, Adebola PA, Edaigbini, SA, Danbauchi S, Sowunmi AC. Experience with prosthetic valve replacement in indigents with rheumatic heart disease in Nigeria: 10-Year Follow-Up. World J Cardiovasc Surg. 2015; 5 (08):75.

[6] Yangni-Angate KH, Meneas C, Diby F, Diomande M, Adoubi A, Tanauh Y. Cardiac surgery in Africa: a thirty-five-year experience on open heart surgery in Cote d'Ivoire. Cardiovasc Diagn Ther. 2016; 6 (1):44-63.

[7] Edwin F, Aniteye E, Tettey MM, Tamatey M, FrimpongBoateng K. Outcome of left heart mechanical valve replacement in West African children - a 15-year retrospective study. J Cardiothorac Surg. 2011; 6:57.

[8] Samiei N, Hakimi MR, Mirmesdagh Y, Peighambari MM, Alizadeh-Ghavidel A, Hosseini S. Surgical outcomes of heart valves replacement: A study of tertiary specialied cardiac center. ARYA Atherosclerosis. 2014; 10 (5):233-237.
[9] Bourguignon T, Bergöend E, Mirza A, Ayegnon G, Neville P, Aupart MR, Marchand M. Risk factors for valve-related complications after mechanical heart valve replacement in 505 patients with long-term follow up. J Heart Valve Dis. 2011; 20 (6):673-80.

[10] Mvondo CM, Pugliese M, Giamberti A, Chelo D, Kuate LM, Boombhi J, Dailor EM. Surgery for rheumatic mitral valve disease in sub-saharan African countries: why valve repair is still the best surgical option. Pan Afr Med J. 2016; 24:307.

[11] Zouaoui W, Ouldzein H, Drissa MA, Essafi N, Meddeb I, Drissa H. [Short- and long-term results of mitral valve replacement by caged-ball and bileaflet mechanical prosthesis (series of 236 consecutive patients with average follow-up of 11 years)]. Ann Cardiol Angeiol. 2009; 58 (2):86-93.

[12] Benedetto U, Melina G, Angeloni E, Refice S, Roscitano A, Comito C, Sinatra R. Prophylactic tricuspid annuloplasty in patients with dilated tricuspid annulus undergoing mitral valve surgery. J of Thorac and Cardiovasc Surg. 2012; 143 (3): 632638 .

[13] Rezahosseini O, Rezaei M, Ahmadi Tafti SH, Jalali A, Bina P, Ghiasi A, Karimi A, Abbasi K, Shirzad M, Davoodi S, Salehi Omran A. Transseptal Approach versus Left Atrial Approach to Mitral Valve: A Propensity Score Matching Study. J Tehran Heart Cent. 2015; 10 (4):188-93.

[14] Al Mosa AF, Omair A, Arifi AA, Najm HK. Mitral valve replacement for mitral stenosis: A 15-year single center experience. J Saudi Heart Assoc. 2016; 28 (4):232-8.

[15] Takano H, Hiramatsu M, Kida H, Uenoyama M, Horiguchi K, Yamauchi T, Kin K, Shirakawa Y, Kaneko M, Daimon T. Severe tricuspid regurgitation after mitral valve surgery: the risk factors and results of the aggressive application of prophylactic tricuspid valve repair. Surg Today. 2017; 47 (4):445-456. 